\title{
Foliar Application: A Thriving and Flourishing Domain in Agriculture
}

\author{
Pushpa C Tomar* and Tanya Kalra \\ Department of Biotechnology, Manav Rachna International Institute of Research and Studies, India \\ *Corresponding author: Dr. Pushpa C Tomar, Associate Professor, Department of Biotechnology, Faculty of Engineering \& Technology, Manav Rachna \\ International Institute of Research and Studies, Faridabad, Haryana, India, 121004
}

Submission: 監 February 20, 2018; Published: 㘹 March 27, 2018

\section{Introduction}

Foliar Application seems to be an upcoming and ongoing research area especially in the field of agriculture. This is been in practice in various parts of the world and proved its positive results in its field [1,2]. Foliar application can be explained as spraying the suitable fertilizer solution (condition is, that it should be water soluble) on the surface of the leaves of growing plants [3]. This practice not only saves quantity of fertilizer used but also improves the uptake of a particular micronutrient by the crops and boosts the yield too. Interaction between crop's genetic potential and the environment in which it grows is detrimental for the yield of a crop [4]. Soil application of nitrogen is a conventional method to supply nitrogen to plants and for improvement in any field adhering to the old ways will not be a better option [4]. In some instances, the availability of urea becomes inadequate for the farmers at sowing time. In such situation the foliar application of plant nutrient is effective and economical for some crops [5]. It has been shown in some studies that uptake of micronutrients directly from plants is more rapid and quicker for better results in yields than soil application[1]. As mentioned above, that the fertilizer should be water soluble for foliar spray and moreover, it should also be noted that the particular crop plant also should be suitable for aerial spray. The best results of foliar application also depends on the soil condition as if soil conditions are unfavourable when micronutrients are needed, it may be desirable to make foliar applications of the plant nutrients [6].

It is more advantageous to apply urea in foliar spray as it depends less on soil conditions, especially in saline or dry soils which can provide hindrance in uptake of nitrogen by plants [6]. In saline soils foliar application avoids a further increase in salt concentration. In waterlogged areas, it prevents the leaching loss of Nitrogen. Foliar spraying is also beneficial in dry conditions where there is little soil moisture, as plants are able to assimilate urea through the leaves $[1,6]$. Just 2 to $4 \mathrm{~kg}$ of urea can be dissolved in 100 litres of water can be effectively used for foliar spray. It has been shown, that foliar application augmented the efficiency of nutrient uptake by 8-9 folds when compared with nutrients applied to soil
[7]. So, when the deficiency symptoms appear foliar application acts as a quick fix for these symptoms. Tests have shown that foliar feeding can increases yields from $12 \%$ to $25 \%$ when compared to conventional fertilization [7]. Tests have been conducted in varied locations under diverse spectrum of environmental conditions.

a) More than $90 \%$ of the fertilizer is utilized by the plant in foliar applied fertilizer. However using a similar amount of fertilizer application to the soil, only 10 percent of it is utilized [8].

b) In the loamy sand, the fertilizers which are applied in foliar way are up to 20 times more effective than fertilizers applied in soil [7].

\section{Foliar: Next Thriving Revolution in Agriculture}

Foliar feeding can prove as boon to agriculture field for correcting not only soil deficiencies but also overcoming the soil's failure to transfer nutrients to the plant under low moisture conditions [8].

Therefore, it could be concluded, that the foliar nutrition can to be a brilliant asset

a) When an immediate response is needed, there can be a supply of nutrients during peak periods of demand through foliar input [2]

b) Nutrients like zinc and iron can be provided, that may not be readily available by root uptake via soil application [2]

c) Sometimes soil applications are not feasible for uptake of nutrients, then foliar feed can provide nutrient source during periods of stress [2]

d) Foliar feed allows flexibility in delivering nutrients that can aid in progress of harvest [5]

e) Giving a nutritional boost to plants at the same time that other foliar chemicals are being applied, thereby minimizing application expenses [8]. 


\section{References}

1. Khan Qadri RW, Khan I, Muzammil JM, Ashraf U, Samin G, et al. (2015) Phosphorous and foliar applied nitrogen improved productivity and quality of potato. American Journal of Plant Sciences 6: 144-149.

2. Tarek A, Hassan El-R (2017) Foliar application: from plant nutrition to biofortification. Env Biodiv Soil Security 1: 71-83.

3. Jamal Z, Humayun M, Ahmad N, Chaudhary MF (2006) Effects of soil and foliar application of different concentrations of NPK and foliar application $\left(\mathrm{NH}_{4}\right)_{2} \mathrm{SO}_{4}$ on different yield parameters in wheat. Journal of Agronomy 5(2): 251-256.

4. Saleem I, Javid S, Sial RA, Ehsan S, Ashfaq AZ (2013) Substitution of soil application of urea with foliar application to minimize the wheat yield losses. Soil Environ 32(2): 141-145.
5. Nafees A, Samiullah K, Aziz O (1993) Response of mustard to seed treatment with pyridoxine and basal and foliar application of nitrogen and phosphorus. Journal of Plant Nutrition 16: 1651-1659.

6. Gooding MJ, Davies WP (1992) Foliar urea fertilization of cereals: a review. Fertilizer Research 32(2): 209-222.

7. Sela Guy (2014) Foliar feeding. Fertilizer management.

8. Mikkelsen R L (2008) Where does foliar fertilization fit in? plant nutrition today. International Plant Nutrition Institute (IPNI), Springer, Vol 3.
Creative Commons Attribution 4.0

International License

For possible submissions Click Here
Submit Article

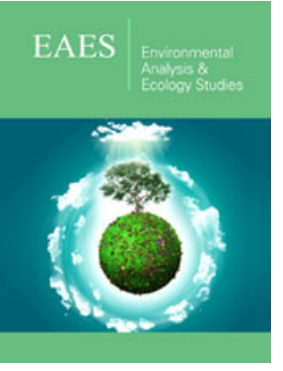

\section{Environmental Analysis \& Ecology Studies}

\section{Benefits of Publishing with us}

- High-level peer review and editorial services

- Freely accessible online immediately upon publication

- Authors retain the copyright to their work

- Licensing it under a Creative Commons license

- Visibility through different online platforms 